\title{
A importância do tempo geológico: desdobramentos culturais, educacionais e econômicos
}

\author{
Cinzia Cervato \\ Universidade Estadual de lowa, \\ Departamento de Ciências Geológicas e \\ Atmosféricas. \\ cinzia@iastate.edu \\ Robert Frodeman \\ Universidade do Norte do Texas, \\ Departamento de Filosofia e Estudos \\ da Religião. \\ frodeman@unt.edu
}

Nota dos Revisores (NR). Original: CERVATO, Cinzia; FRODEMAN, Robert. The significance of geologic time: cultural, educational, and economic frameworks. The Geological Society of America, Special Paper, n. 486, p.19-27, 2012. Aceito para publicação pela GSA em 07/11/2011. doi: 10.1130/2012.2486(03). Texto traduzido por Maria Cristina Briani e Pedro Wagner Gonçalves. Revisado por Pedro Wagner Gonçalves e Carlos Alberto Lobão Cunha.

\begin{abstract}
The discovery of geologic time revolutionized scientific thinking and led to the development of the modern Earth sciences. Less appreciated, however, is the fact that geologic time has had far-reaching cultural and societal consequences that go well beyond its founding influence upon the geosciences. This essay summarizes the literature describing the difficulties students encounter in understanding deep time, provides an overview of the historical development and cultural relevance of deep time, and suggests ways to increase students' understanding of the significance of geologic time. Citation: Cervato C., Frodeman R. 2014. A importância do tempo geológico: desdobramentos culturais, educacionais e econômicos (tradução). Terræ Didatica, 10(1):67-79. <http://www.ige.unicamp.br/terraedidatica/> .
\end{abstract}

KEYWORDS: Earth Sciences, philosophy of geology, geologic time.

RESUMO A descoberta do tempo geológico revolucionou o pensamento científico e conduziu ao desenvolvimento das modernas Ciências da Terra. Apesar disso, pouca atenção é dada para as consequências culturais e sociais de longo alcance do tempo geológico, que vão bem além de sua influência sobre as Geociências. Este ensaio resume a literatura que descreve a dificuldade que os estudantes encontram para compreender o tempo profundo, fornece uma visão geral do desenvolvimento histórico e a relevância cultural do tempo profundo, e sugere maneiras de aumentar a compreensão dos alunos sobre o significado do tempo geológico.

PALAVRAS-CHAVES: Ciências da Terra, Filosofia da Geologia, tempo geológico. 


\section{INTRODUÇÃO}

O que, então, é o tempo? Se ninguém me pergunta, eu sei o que é, mas se eu quiser explicar a quem me perguntar, eu não sei. - Santo Agostinho.

Somente um pequeno número de ideias mudou o caminho da história. Uma foi a substituição da visão de mundo geocêntrica pela heliocêntrica de Copérnico. A descoberta do tempo geológico feita por Hutton e Werner foi outra. O espaço copernicano, bem como as ramificações do tempo huttoniano ecoam na cultura científica, econômica, política e religiosa. A teoria da evolução da Biologia seria impossível sem as dimensões do tempo geológico (Gould 1987), tampouco podemos começar a entender adequadamente os desafios econômicos e ambientais sem a perspectiva do tempo profundo (o fim da era do petróleo, a perspectiva de futuras alterações climáticas, a perda da biodiversidade, a fatalidade das taxas atuais de consumo). Finalmente, o tempo geológico apresenta um desafio fundamental para muitos em termos de suas implicações relativas ao lugar da humanidade no esquema maior de todas as coisas. ${ }^{1}$

Tempo geológico e Geociências ocupam papel central na cultura contemporânea. Por isso é irônico que professores relatem dificuldades para ensinar o conceito de tempo geológico. Algumas evidências das dificuldades de estudantes parecem piada, porque sugerem que não há sentido de realidade no entendimento do tempo profundo. A literatura mostra que estudantes de licenciatura, professores, bem como alunos no início da universidade confundem eventos no tempo geológico em ordem de magnitude, juntam fatos separados no tempo, tais como convívio de humanos e dinossauros, e têm pouca percepção de taxas de mudança (Trend 2001; Dodick e Orion 2003a, 2003b, 2006; Libarkin, Kurdziel, Anderson 2007). Além disso, estudantes frequentemente não se mostram interessados em melhorar seu senso sobre a extensão do tempo geológico. Para eles, pouco parece estar em jogo.

1 NR. Rossi (1992, original italiano de 1979) detalhadamente reconstrói 0 caminho, os contextos intelectuais e os obstáculos culturais da elaboração da ideia de tempo geológico no pensamento ocidental a partir do século XVII. Indica quanto esse conceito foi entrelaçado com 0 pensamento religioso, político e linguístico. Compara a revolução do tempo geológico à revolução do espaço copernicano. Mostra como muitos pensadores do século XVIII se envolveram no adensamento da noção de tempo da natureza além de Abraham Gottlob Werner e James Hutton. Georges-Louis Leclerc (mais conhecido como Buffon), Denis Diderot, Immanuel Kant aceitaram as sucessivas revoluções do mundo e suas marcas deixadas na natureza - evidência essencial para aumentar a noção de tempo.
Como mostra a epígrafe de Santo Agostinho (354-430), a dificuldade não é circunscrita aos estudantes, ou mesmo à extensão do tempo geológico. O conceito de tempo em si é notavelmente enganoso e, simultaneamente, de crucial importância. Em um dos mais importantes trabalhos de Filosofia do século XX, Ser e o tempo (1927, reimpresso em 1962), Martin Heidegger constrói toda a sua argumentação em torno da importância do tempo, alegando que o nosso sentido do significado da vida depende de nosso senso de temporalidade. No prefácio do livro, Heidegger declara: "nossa hipótese provisória é que o tempo é o horizonte para qualquer possível entendimento do ser, o que quer que seja." Seu argumento - como será discutido neste texto - é que nosso senso de realidade e nossa cultura dependem crucialmente de nossa concepção de tempo.

Neste ensaio, procuramos despertar uma valorização do tempo geológico colocando-o dentro de um contexto social mais amplo. O tempo geológico é uma das ideias culturalmente mais relevantes na história do pensamento. Apesar de não ser facilmente compreendido, a variedade de dimensões do tempo geológico (p.ex., o período desde o último máximo glacial, as taxas de evolução, o período de tempo que leva para erodir montanhas ou substituir espécies perdidas) oferece perspectivas de uso prático para pessoas de negócios, políticos e cidadãos. Além disso, mesmo a perspectiva mais simples do tempo geológico - enxergar nossas vidas e nossas paisagens dentro do âmbito de uma extensão maior de tempo - pode encher nossos alunos de admiração para a maravilha que é a vida na Terra. Este ensaio, portanto, busca ajudar os professores a apresentar bem o significado cultural maior das dimensões do tempo geológico, por meio do currículo. A noção de tempo geológico é central para as Geociências e para o empreendimento científico em geral e o alcance de suas implicações não pode ser limitado à comunidade científica. Uma ideia mais ampla de tempo geológico, desde detalhes radiométricos a perspectivas de políticas públicas, deve ser ensinada tanto para estudantes de Geociências como para os de qualquer outro campo. A força dessas ideias é crucial para informá-los e preparálos para suas vidas como cidadãos e consumidores. Os especialistas em Geociências também precisam compreender esses pontos, já que também viverão como cidadãos e consumidores, além de cientistas. Além disso, em suas carreiras profissionais eles serão os únicos a transmitir esses elementos aos 
seus concidadãos, bem como serão responsáveis pela preparação da próxima geração de estudantes. ${ }^{2}$ Dentro desse quadro, descreveremos brevemente a literatura sobre psicologia evolucionária e cognitiva sobre as causas conhecidas das dificuldades humanas em compreender o conceito de ampla escala de tempo e incorporar uma visão de longo prazo na tomada de decisões.

A literatura pedagógica sobre o tempo geológico centrou-se no entendimento dos processos científicos e fenômenos limitados pelo tempo geológico. Este ensaio traz uma nova perspectiva para contextualizar o tempo geológico fora das abordagens tradicionais. No que segue iremos (1) resumir o estado da arte da pesquisa e do ensino do tempo geológico, (2) apresentar o contexto histórico e filosófico para o desenvolvimento do conceito de tempo profundo, (3) oferecer um quadro da sua relevância em termos de três grandes dimensões: o tempo geológico como motor econômico, como ferramenta política e como padrão cultural. Ao longo do artigo oferecemos sugestões sobre como os pontos podem ser operacionalizados no currículo, na pesquisa e nos setores públicos e privados.

Para encerrar a introdução é importante distinguir os termos tempo geológico e tempo profundo. Embora muitas vezes usados como sinônimos, os termos apontam para certos aspectos diferentes do tempo. Tempo profundo, cunhado por Thomas Carlyle em 1832 e mais tarde popularizado por McPhee em 1981, enfatiza o trecho vertiginoso do passado que vai além da cultura humana, ou seja, fatos mais antigos do que 8.000 anos. Em contraste, tempo geológico destaca a maneira como os geocientistas contam o tempo - uma escala de

2 NR. Diferentes reflexões sobre a Filosofia e Metodologia da Geologia enfatizaram a relevância do conhecimento da Terra entre as ciências e seus papéis educacionais. Um dos argumentos mais antigos foi exposto por Potapova (2008, original russo de 1963) ao caracterizar a abrangência do campo científico entre as ciências e tecnologias, enfatizar o lado temporal e histórico de estudo do planeta, criticar a excessiva especialização, bem como assinalar 0 caráter sistêmico e integrado para interpretar a Terra. Cuello (1988) esmiuçou o papel do conhecimento geológico para integrar distintas áreas de conhecimento no ensino. 0 caráter integrador tem múltiplas funções cognitivas e ajuda a contextualizar conteúdos de diferentes campos de ensino, tais como Matemática, Física, Química. Carneiro, Toledo e Almeida (2004) continuam um debate já enfrentado por outros autores (p.ex., Alvarez et al. 1992) e defendem a relevância educacional das Geociências para formar alunos aptos para 0 mundo científico e tecnológico, bem como capazes de interferir de forma cidadã no mundo. Ver: Potapova M.S. 2008. Geologia como uma ciência histórica da natureza. Terrae Didatica, 3(1):86-90. Cuello Giijón A. 1988. La Geología como area interdisciplinar. Henares Revista de Geología, 2:367-387. Carneiro C.D.R., Toledo M.C.M., Almeida F.F.M. 2004. Dez motivos para a inclusão de temas de geologia na educação básica. Rev. Brasil. Geoc., 34:553-560. Alvarez Suárez, R. et al. 1992. Treinta razones para aprender más Geología en la educación secundaria. In: Simposio Enseñanza de la Geología; 7; Santiago de Compostela; Actas... p.231-240. tempo em que milhões de anos são tratados como algo ordinário. Em algumas ocasiões, os paleontólogos usam o tempo profundo para distinguir sua própria perspectiva de tempo daquela usada pelos biólogos. Em outros casos, os geocientistas usam tempo profundo como sinônimo de tempo pré-Quaternário, uma época em que a Terra não tinha a aparência atual em termos de biota, distribuição continental e de climas (veja Sadler 2008). Nesse contexto, embora historiadores, biólogos e arqueólogos façam uso do tempo e escalas geológicas, o tempo profundo tornou-se reino quase exclusivo dos geocientistas.

\section{ENSINANDO 0 TEMPO GEOLÓGICO}

Embora tempo geológico seja um conceito fundamental das Geociências, é no campo da Estratigrafia que ele se mostra mais central. Dentro da comunidade estratigráfica hoje, a investigação concentra-se no estudo de taxas, em vez de datas, e na construção de linhas de tempo de eventos ao invés da calibração de escalas estáticas padronizadas de tempo (ver, p.ex., Sadler e Cervato 2011). Grupos científicos tais como Earthtime (www. earth-time.org) sequenciam o tempo geológico ao integrar geocronologia de alta precisão (as datas) e cronoestratigrafia quantitativa (as taxas) com o objetivo de restringir idades de eventos que ocorreram centenas de milhões de anos atrás com a precisão da ordem de centenas de milhares de anos (aproximadamente $0,1 \%$ da idade) ao invés de métodos tradicionais que confinam em milhões de anos. ${ }^{3}$

O aumento da precisão é objetivo de pesquisa louvável da comunidade de estratígrafos, mas é improvável que seja de muito interesse para os não iniciados. Nosso desafio central é encontrar novas maneiras de transmitir um entendimento amplo e rico de tempo geológico para estudantes por meio do currículo. Enquanto alguns obstáculos no ensino do tempo geológico sejam fruto de anedota, há um crescente número pesquisas no assunto que vão desde o nível elementar ao universitário, a professores em treinamento e em

3 NR. Van Loon (1999) sugere que a subdivisão estratigráfica, especialmente os limites lito e bioestratigráficos, está relacionada aos propósitos e abordagem metodológica dos pesquisadores. Aqueles que examinam processos enfatizam a continuidade e a lenta mudança cronológica entre unidades e horizontes lito e bioestratigráficos. De outro lado, aqueles que utilizam modelos reforçam que o registro litoestratigráfico está marcado por mudanças abruptas e um bom exemplo dessas mudanças rápidas de processos é a mudança climática (ver: VAN LOON, A.J. The meaning of 'abruptness' in the geological past. Earth-Science Reviews, 45:3-4). 
serviço (p.ex., Ault 1982; Schoon 1992, Trend 2001, Dodick e Orion 2003a, 2003b, Libarkin et al. 2005, Libarkin et al. 2007)

Trabalhos de Libarkin e outros apóiam a ideia de que alunos universitários apresentam as mesmas dificuldades de crianças mais novas no entendimento do tempo profundo (p.ex., Friedman 2005). Libarkin et al. (2007) descobriram que estudantes universitários de 43 diferentes instituições nos EUA sustentam uma série de concepções alternativas sobre tempo profundo e a vida na Terra. Os autores apontaram que embora a maioria dos estudantes conseguiu situar eventos como a origem da vida, a extinção dos dinossauros e a evolução humana na sequência correta, os mesmos tiveram uma má compreensão da escala real de tempo entre esses eventos.

\section{Objetivos de aprendizagem}

Em face disto, professores de Geociências identificam uma série de ferramentas conceituais, estratégias e referências úteis para lidar com o desafio de ensinar tempo geológico. Por exemplo, os Parâmetros Nacionais de Educação em Ciências dos EUA recomendam que a partir do $5^{\circ}$ ano os estudantes devem desenvolver um entendimento da história da Terra e dos princípios fundamentais da Estratigrafia, incluindo uma compreensão básica do uniformitarismo e catastrofismo. Estudantes nessa idade podem também conhecer como fósseis servem de evidência de mudanças ambientais ocorridas no tempo, bem como ser introduzidos nas escalas e taxas de processos terrestres (de segundos, para explosões vulcânicas, a centenas de milhões de anos, para erosão e aplainamento de cadeias de montanhas; ver: National Research Council (1996); Libarkin et al. (2007). Compreender taxas de processos geológicos envolve desafios significativos para as Geociências, bem como para a sociedade. Quanto tempo é necessário para a matéria orgânica em decomposição se transformar em combustíveis fósseis? Qual é a velocidade das placas tectônicas, produzindo terremotos e mudanças na paisagem? Qual a frequência de inundações em grande escala? ${ }^{4}$

\footnotetext{
$4 \quad$ NR. Atividade que desenvolve a ideia de tectônica de placas associada à migração de continentes, mudança do clima e da biota durante 0 Fanezoróico é apresentada por Gonçalves e Carneiro (2008). Apoiada na História e Filosofia da Geologia torna relações de processos e sua duração no tempo mais claras. Ver: Gonçalves P.W., Carneiro C.D.R. 2008. La danza de los continentes en el tiempo geológico. Enseñanza de las Ciencias de la Tierra, 16:107-116
}

\section{Obstáculos e concepções incorretas}

Identificamos três obstáculos principais para os estudantes compreenderem o sentido de tempo geológico. Em primeiro lugar, tempo profundo envolve escalas e eventos distantes da experiência humana cotidiana. Relacionado a isso está a raridade de eventos geológicos catastróficos que desafiem a capacidade imaginativa dos estudantes. Os seres humanos tendem a zerar a probabilidade de eventos raros, tais como acidentes de carro e doenças que ameaçam a vida (Tversky e Kahneman 1974). Em grau ainda maior, fenômenos como terremotos, enchentes e erupções vulcânicas são vítimas do mesmo hábito mental. O principal desafio de professores de Geociências é ajudar os estudantes a alongar seu horizonte temporal para tornar eventos geológicos relevantes para eles.

Em segundo lugar, tempo profundo trata com números exponenciais e quocientes numéricos que são notórios desafios aos estudantes. Em uma época em que calculadoras são onipresentes, um subproduto de nossa cultura tecnológica é a erosão da capacidade do pensamento operar com magnitudes e grandezas (elementos incorporados ao tempo geológico). Calculadoras e computadores são maravilhosos por rapidamente fornecerem respostas precisas, mas desestimulam os estudantes a desenvolver o tipo de orientação de consciência que os ajuda a saber se uma resposta faz sentido. O tempo geológico tanto requer, como ajuda, a desenvolver um senso de conhecimento como reconhecimento (Foltz 2000), por intermédio do qual os estudantes aprendem modos de tratar problemas.

O terceiro e último obstáculo na compreensão do tempo geológico é causado pela proeminência dos ensinamentos religiosos que fazem alguns estudantes resistentes ao conceito de uma Terra antiga. Nos EUA, $45 \%$ da população acredita que os seres humanos foram criados em sua forma atual por Deus em algum momento dos últimos 10.000 anos (Gallup 2004). Salientamos, no entanto, que a atração pelo criacionismo não é simplesmente uma questão de dogma religioso. Os seres humanos são seres narrativos (McIntyre 1981), buscam o sentido da finalidade (Kermode 1967), pois desejam colocar a si mesmos dentro de uma narrativa que dê significado e propósito claros para suas vidas. Em contraste com a história cristã, modernas descobertas geológicas e biológicas descrevem processos naturais randômicos e sem qualquer propósito pré-definido (p.ex., Gould 1987, Frodeman 1995, 
2003). Os educadores deveriam reconhecer - a si mesmos e a seus alunos - que a aparente falta de propósito de eventos ao longo do tempo geológico é profundamente inquietante para muitas pessoas. ${ }^{5}$

Um argumento adicional afirma que a valorização dos homens sobre o tempo profundo é comprometida porque somos predispostos pela evolução a preferir compensações de curto prazo versus de longo prazo (p.ex., Penn 2003, McClure et al. 2004). Em essência, a alegação é que os circuitos neurais em nosso cérebro foram desenhados pela seleção natural para resolver os problemas que nossos antepassados enfrentaram durante a nossa história evolutiva (Tooby e Cosmides 1995). A neuroeconomia ainda tentou quantificar a taxa de retribuição de animais e seres humanos que os faz escolher entre as opções de curto e de longo prazo diante de opções postas pela vida. Apesar dessas considerações, temos dúvida sobre a importância dos argumentos sócio-biológicos para compreender dificuldades das pessoas diante do conceito de tempo geológico.

\section{Aumentando a compreensão de estudantes sobre conceitos temporais}

Livros de texto normalmente utilizam analogias de $24 \mathrm{~h}$ ou de 1 ano para ajudar os estudantes a compreender o período de 4,5 bilhões de anos (4,5 Ga) de história da Terra (p.ex., comparando 1 ano com a largura de uma moeda de um centavo, a extensão do tempo geológico circundaria a terra mais de 2 vezes, ou a uma pilha de notas de dólares, uma pilha de $460 \mathrm{~km}$ de altura; ver http://www. kokogiak.com/megapenny/). Dentro desta vasta extensão de tempo, os seres humanos ocupam apenas o montante mais insignificante, um pensamento assustador para os estudantes que acham mais manipulável tratar de uma jovem Terra de 6.000 anos. Mesmo sendo muito difundidas, não está claro se as analogias são efetivas no sentido de aumentar a percepção dos seres humanos diante do tempo geológico. Isso é uma área a ser futuramente investigada (p.ex., Dodick 2007).

Tendências recentes nos estudos de educação primária em história não enfatizam a ideia de cronologia absoluta; ao invés disso, enfocam na ideia de tempo relativo ou no sequenciamento de eventos (p.ex., Levstik, Barton 2005). Na Geologia, a antiga ênfase nos grandes números e eventos não 5 NR. Tradução para o português: Frodeman R. 2010. 0 raciocínio geológico: a Geologia como uma ciência interpretativa e histórica. Terræ Didatica, $\mathbf{6}(2): 85-99<$ http://www.ige.unicamp.br/terraedidatica/> familiares (p.ex., pedir para memorizar toda a escala do tempo geológico) explica algumas dificuldades dos estudantes em compreender o tempo profundo. O consenso geral atual é de que os estudantes sentem-se mais confortáveis situando eventos ou fósseis na sequência de tempo relativo por meio de modelos espaciais, ou seja, modelos de tempo baseados na lógica (p.ex., Trend 2001, Dodick e Orion 2003a, 2003b, 2006). Tarefas específicas e idade de objetos podem interferir no desafio posto pelo tempo absoluto e datação, ou para definir eventos no tempo. Libarkin et al. (2007) sugerem que números muito grandes requerem pensamento matizado para construir pontes entre diferentes escalas, da escala da experiência humana até a magnitude do tempo geológico. Cientistas cognitivos utilizam com frequência metáforas espaciais em seus estudos sobre concepções humanas de tempo, assumindo que os seres humanos compreendem mais facilmente espaço do que tempo. Assim, p.ex., Boroditsky (2000) distinguiu entre metáforas de movimento do ego, nas quais o sujeito é ativamente envolvido no processo de tempo e metáforas de movimento temporal, nas quais os seres humanos experimentam como observadores eventos relationados ao tempo. Geocientistas (e estudantes) experimentam o tempo em ambos os sentidos: andar por afloramentos ou ao longo de núcleos de sedimentos é um exemplo de eu em movimento, enquanto eventos de curta duração que ocorrem em uma escala de tempo humana, como p.ex., furacões e terremotos, são experimentados como o tempo em movimento. Cientistas cognitivos tendem a representar o tempo como unidimensional, ao passo que a maioria das representações de eventos em escalas de tempo geológicas é multidimensional (p.ex., uma espiral do tempo, as cores da escala do tempo geológico, registros de dados e eventos postos lado a lado em linha do tempo, árvore filogenética), Dodick (2007). Uma fonte adicional de confusão é o uso comum de linhas de tempo horizontais no ensino de história e cronologia para crianças, enquanto os geólogos experimentam o tempo verticalmente. Em uma linha do tempo geológico, o presente sempre está no topo, enquanto que uma linha de tempo horizontal utilizada na história pode fluir da esquerda para direita, ou vice-versa. Finalmente, e sem dúvida o mais confuso, nas linhas de tempo geológico o tempo flui para trás, ao passo que o tempo da experiência cotidiana flui para frente (Dodick, Orion 2006). 


\section{Aumento da motivação de estudantes em relação ao tempo geológico}

As técnicas aqui resumidas oferecem importante ajuda para aulas. Contudo, mais do que o mapeamento de habilidades cognitivas ou o desenvolvimento de técnicas geopedagógicas, acreditamos que haverá mais êxito em ajudar estudantes a compreender o tempo geológico se o ensino explorar mais questões de contexto, motivação e interesse. Problemas de motivação (por que eu deveria me importar com o tempo profundo?) abordadas por Zen (2001) e Frodeman (2003) apontam para elementos-chaves de interesse social mais amplo no conceito de tempo geológico.

Consideremos, p.ex., a Lei das Fácies de Walther, de que a sucessão vertical das fácies em rochas refletem mudanças laterais dos ambientes. A ideia chave de que unidades de tempo podem cortar unidades de rochas auxilia os estudantes a colocarem a Terra em movimento: as camadas do afloramento de folhelho negro e calcário revelam a transgressão marinha sobre o que hoje é uma paisagem desértica. Rochas tornam-se peças do tempo petrificado (marcas ossificadas do passado geológico), entidades estáticas tornam-se cenas dinâmicas na mente dos estudantes. Da mesma forma, a compreensão das maneiras pelas quais as taxas geológicas operam desde o muito lento (a formação de montanhas) ao instantâneo (um terremoto) põe a atividade humana no contexto geológico, algo relevante para questões sociais, econômicas e políticas mais amplas.

A seguir, procuramos colocar o tempo geológico dentro desse contorno humanístico e político ampliado. Adicionalmente, acreditamos que isso contribui para o rigor lógico do ensino do tempo geológico. Para perceber isso, considere a questão da definição do grau adequado de rigor de um evento em tempo geológico. O grau necessário de precisão não pode ser uma definição meramente científica. O grau de precisão é inevitavelmente dependente do contexto social (o que, é claro, inclui a sociedade formada por, p.ex., um grupo de estatígrafos patrocinada em algum grau pela indústria ou pelo poder legislativo).

Graduados de áreas não científicas terão necessidades e interesses distintos dos graduados de Geociências (nem melhores, nem piores), da mesma forma que o mercado de capitais requer diferentes graus de exatidão para identificar o ponto provável (digamos) do pico máximo de produção de petróleo comparado ao timing da mudança climática. Devemos moldar nossas discussões de tempo geológico no âmbito do contexto e interesse humanos, oferecendo relatos divergentes de como as diferentes perspectivas temporais são relevantes para grupos diferentes de alunos. A importância ou o impacto mais amplo dos eventos ao longo do tempo geológico encontra-se assim entremeada no tecido da Educação em Geociências.

\section{PEQUENA HISTÓRIA FILOSÓFICA DO TEMPO GEOLÓGICO}

Para compreender esse impacto mais amplo, considere o desenvolvimento histórico do conceito de tempo geológico. Como Kant observou há mais de 200 anos em Crítica da razão pura (1881), espaço e tempo formam parte da arquitetura básica de nosso pensamento. Uma mudança na nossa compreensão dessas estruturas fundamentais afeta todos os aspectos de nossas vidas. Entretanto, mesmo que os dois sejam quase por definição de igual importância, a revolução copernicana do espaço tornou-se um marco intelectual, ao passo que a revolução huttoniana passou, se não desapercebida, apenas parcialmente notada como um ponto de referência cultural. $^{6}$

A descoberta do tempo geológico por James Hutton no final do século XVIII - um período de tempo de tamanha duração que o conduziu à frase "sem vestígio de início, sem prospecto de fim" anunciou uma revolução científica e cultural. O tempo geológico representa muito mais do que um fato aritmético. Ele permite atribuir sentido ao afloramento, que o enxerguemos como uma foto instantânea do tempo, um ambiente preservado na rocha. Talvez isso seja a maior dádiva que um geólogo pode oferecer: ensinar os estudantes a reviver paisagens. ${ }^{7}$

6 NR. Edição brasileira: KantI. 2012. Crítica da razão pura. Petrópolis: Vozes, 624p. (Tradução por Fernando Costa Mattos).

7 NR. No pequeno texto lido na Real Sociedade de Edimburgo em 1790 James Hutton expressa suas principais preocupações com os ciclos e revoluções da Terra. 0 relato de viagem feita a Aberdeen em 1785 sintetiza 0 esforço para aclarar a origem dos granitos. As duas palestras realizadas em 1785 para expor a teoria da Terra tinham deixado clara a necessidade de provas de campo. Durante sua vida, observando e descrevendo sua coleção de amostras ao microscópio, Hutton definiu os marcos essenciais de sua teoria sobre 0 calor interno do planeta: para ele não havia dúvida que 0 calor era responsável, primeiro, pela consolidação das rochas e, segundo, pelo levantamento dos continentes. Mais claramente do que outros contemporâneos estimou o papel essencial da erosão fluvial. A união de calor interno e erosão criou a ideia de ciclos da natureza. Sua amostra de granito gráfico ilustrou as palestras de 1785 e deixou patente a necessidade de dados adicionais. 
A consciência de tempo geológico é ferramenta muito poderosa e implica muito mais. Ao reorientar nosso sentido de tempo, a Geologia nos apresenta uma nova concepção de nossa consciência de realidade. Como Heidegger argumentou, é nosso sentido de tempo - tão indefinido e inconsciente quanto possa ser-que determina o tipo e a maneira das coisas que consideramos reais ou substanciais.

Um exemplo pode ajudar a aclarar o assunto. Nossa definição atual de verdade (ou seja, o padrão científico) pressupõe um entendimento específico de tempo: definimos realidade como aquilo que pode ser produzido (e reproduzido) devido a uma demanda determinada. Isso faz com que qualquer coisa que permaneça dependente do tempo seja epistemologicamente suspeita (p.ex., Geologia Histórica). Dessa forma, os resultados das ciências experimentais ou de laboratório são considerados o padrão ouro da verdade. Aqueles aspectos da realidade que rejeitam a repetição exata - os insights das ciências históricas, mas também decisões políticas ou aquele momento à beira mar quando a luz está perfeita - serão definidas como subjetivas e não exatamente reais. Da mesma forma, se definirmos a realidade econômica em uma única escala de tempo - digamos, em termos de lucros do último trimestre - então o preço atual do barril de petróleo (cerca de US $\$ 100 /$ barril, dezembro de 2011) pode ser uma medida realista de seu valor, mas visto a partir de uma perspectiva informada pelo tempo profundo a queima de gasolina em um veículo

As duas palestras, março e abril de 1785 foram apoiadas em estudos de amostras (Hutton 1788). Mas o fazer Geologia estava mudando naquela época e passou a valorizar a atividade de campo. Hutton percebeu os motivos epistemológicos para coletar dados diretamente na paisagem (ver Hutton J. 1788. Theory of the earth; or an investigation of the laws observable in the composition, dissolution, and restoration of the land upon the globe. Transactions of Royal Society of Edinburgh, 1(2):209-304).

Entre 1785 e 87, sucessivas excursões foram feitas, uma delas para Aberdeen que identificou o contato do granito no vale do rio Tilt. Mais de uma tonelada e meia de amostras foram coletadas. Observações de contatos e conclusões foram expostas à Sociedade Real de Edimburgo em 1790 (Hutton 1794). Os ciclos de erosão e levantamento de continentes evidentemente não estariam circunscritos a poucos milhares de anos, como 0 próprio Hutton tinha consciência, mas a escala de tempo que emergia era mais uma dedução do que uma preocupação crucial. Apesar disso, atualmente esta escala de tempo é muito mais valorizada que os demais construtos huttonianos (ver Hutton J. 1794. Observations on granite. Transactions of Royal Society of Edinburgh, 3(2):77-85).

Hutton ao lado de outros naturalistas daquela época contribuiu para adensar 0 tempo da natureza. William Smith, Buffon, Georges Cuvier, Alexandre Brongniart mudaram o modo de trabalhar, consideraram relevante observar diretamente a paisagem. A um só tempo, isso mudou o modo de interpretar a natureza e ajudou a mudar o modo como a sociedade via os estudos da natureza (e seus nexos com a mineração). Esse novo fazer científico trouxe entre seus efeitos a consciência do longo tempo da história da natureza, 0 tempo profundo que abalou convicções e possibilitou a emergência de outras ideias radicais (evolução biológica, levantamento de montanhas etc.) esportivo torna-se uma extravagância.

Uma tentativa antiga de medir a idade da Terra foi feita pelo Bispo irlandês James Ussher no século XVII. Baseado em cálculos retirados da Bíblia, Ussher identificou o primeiro dia da Criação como princípio com a escuridão que precedeu o domingo 23 de outubro de 4004 aC (Ussher 1650). Em 1669, Nicolau Steno descreveu as leis estratigráficas de superposição, horizontalidade original e relações transversais a partir de observações de campo feitas na Toscana. No final do século XVIII, a descoberta da imensidão do tempo geológico de Hutton foi o produto de mais de 30 anos de considerações sobre os afloramentos de sua fazenda de Berwickshire. Além disso, ao mesmo tempo em que Hutton estava trabalhando na Escócia, Abraham Werner na Saxônia (Alemanha) percebeu a importância de distinguir unidades lito e cronoestratigráficas. Werner percebeu que um determinado tipo de rocha rastreado ao longo da paisagem pode registrar distintos momentos no tempo, como ambientes deposicionais se deslocam através de uma bacia. ${ }^{8}$

Embora geralmente considerada como simples questão de estratigrafia, a importância cultural da visão de Werner provou-se equivalente à descoberta de Hutton do tempo profundo. A inovação de Werner foi perceber que era possível definir entidades pelo tempo ao invés de fazê-lo em termos das características das coisas em si (p.ex., rochas). Naturalmente, a sabedoria popular sempre entendeu algumas coisas em termos de categorias temporais - plantação, colheita, e os ciclos da vida humana - mas o pensamento conceitual formal foi há muito guiado pelas ideias de Platão e Aristóteles de que as categorias de pensamento necessitavam permanecer fora de efeitos corruptores do tempo. ${ }^{9}$

8 NR. A conturbada trajetória intelectual e pessoal de Steno, de certo modo, assinala sua contribuição decisiva para o pensamento geológico e especialmente para o tempo geológico. 0 nexo entre objetos naturais e corpos rochosos com a acumulação do tempo da natureza acha-se na base da organização das Ciências Geológicas. Seus contemporâneos da Sociedade Real de Londres perceberam 0 alcance de suas conclusões apoiadas em observações da Toscana e Robert Hooke providenciou a tradução do pequeno Prodomus para o inglês. Apesar disso, depois do século XVII, Steno permaneceu esquecido até ser descoberto somente no século XIX por Alexander von Humboldt e Jean Baptiste Élie de Beaumont que 0 trouxeram para 0 público geológico e ajudaram a criar 0 mito de Fundador da Geologia. Ver: Thomsen E. 2009. Niels Stenses - Steno, in the world of collections and museums. In: Rosenberg G.D. Ed. The Revolution in Geology from the Renaissance to the Enlightenment. Boulder (CO): Geological Society of America, p.93-106. E: Rossi P. 1992. Os sinais do tempo: história da Terra e história das nações de Hooke a Vico. São Paulo: Companhia das Letras, 387p.

9 NR. 0 ponto foi desenvolvido por Frodeman (2004) quando descreveu as características das atividades de campo da Geologia. 0 argumento opôs dois espaços da pesquisa científica, o laboratório e 0 campo. 0 primeiro corresponde ao esforço de recriar a natureza em condições controladas nas 
Os achados de Werner contribuíram para um dos aspectos mais característicos da cultura moderna. Desde meados do século XIX, temos vivido uma cultura permeada pelo tempo: após Werner, nós agora definimos a verdade em termos do tempo. Por exemplo, com notáveis exceções (as ciências experimentais, o fundamentalismo religioso), nossa cultura adotou o historicismo, a crença de que, ao invés de existirem padrões invariáveis de verdade, cada afirmação só pode ser entendida em relação ao período histórico em que ela é feita. O historicismo é normalmente associado aos antropólogos Franz Boaz e Ruth Benedict, mas suas raízes na cultura vinculam-se a Hutton, Werner e ao filósofo germânico Georg Hegel. ${ }^{10}$

Na Fenomenologia do Espírito (1805, reimpresso em 1977), Hegel analisou toda a história da cultura humana em termos da evolução progressiva da cultura. Hegel defendeu que toda história humana foi inconscientemente dirigida para a finalidade de autoconhecimento (racionalismo) e autodeterminação (democracia). No início do século XX, a Antropologia pluralizou o ponto de vista hegeliano: mais do que ver o desenvolvimento histórico da cultura humana como indicador de um fim comum, Benedict, estudante de Boaz, argumentou que cada cultura particular apresenta uma configuração única que não pode ser julgada por meio de parâmetros universais. Cada imperativo da cultura moral forma um todo distinto; a moral tornou-se relativa aos valores de culturas individuais - o que hoje é denominado relativismo cultural. ${ }^{11}$

Correndo o risco de exagerada simplificação, podemos resumir esses pontos com uma tabela

quais a Matemática e a ordem parametrizada assegurem a regularidade de mudanças e transformações.

Nesse domínio leis abstratas adquirem validade universal. Mas o mundo da política, da história e da contingência continua existindo. Geologia, na qual as transformações dependem da temporalidade, se aproxima daquilo que está sujeito à história. 0 fazer Geologia está intrinsecamente ligado à peculiaridade da atividade de campo (Ver Frodeman R. 2004. Philosophy in the Field. In: Foltz B.V., Frodeman R. Ed. Rethinking nature: essays in environmental philosophy. Bloomington, IN: Indiana University Press, p.149-164).

10 Agora, se Heideegger está correto ao argumentar que nossa vida é profundamente afetada pelas mudanças em nosso entendimento de tempo, então devemos esperar que outras inovações, p.ex., o desenvolvimento de cronômetros, teria tido efeitos culturais e houve: a consciência ocidental de tempo foi profundamente afetada pela distribuição de relógios durante os décimo segundo e décimo terceiro séculos nas culturas muçulmanas e cristãs. A rede resultante do relógio, entretanto, matematizou o tempo, tornando possível para pessoas planejar o tempo e, de fato, separar fluxo de mudança física. Em linguagem filosófica, podemos dizer que o relógio mecânico platonizou nossa experiência ao criar unidades matemáticas mais reais do que a realidade vivida.

11 NR. Edição brasileira: Hegel G.W.F. 2011. Fenomenologia do espírito. Petrópolis: Vozes, 552p. (Tradução por Paulo Meneses) das mudanças culturais causadas pela revolução do conceito de tempo de James Hutton (Tab. 1). Antes da descoberta do tempo profundo, o estudo da Terra era limitado à Mineralogia; a idade da Terra era restrita a 6.000 anos; o universo era visto como cheio de propósitos e finalidades e a ética era entendida como consistindo de um padrão universal. Todos esses fatores mudaram no rescaldo da revolução Huttoniana.

Tabela I. Mudanças culturais geradas pela Revolução do conceito de tempo de James Hutton

\begin{tabular}{l|l|l}
\hline & Pré-Hutton & Pós-Hutton \\
\hline Disciplina & Mineralogia & Geologia \\
\hline Duração & 6.000 anos & $4,5 \mathrm{Ga}$ \\
\hline Significado & Teológico & Não teológico \\
\hline Etica & Universalista & Historicista \\
\hline
\end{tabular}

\section{UMA ESTRUTURA TRIPARTITE}

Qual é o resultado prático desse breve apanhado sobre origens e significado cultural do tempo geológico? Identificamos três meios que podem motivar os estudantes a aprender sobre o tempo geológico. Propomos três categorias para expandir e compreender o tempo geológico: econômica, política e cultural.

Tradicionalmente - ou seja, até o final do século XIX - economia e política formavam um só objeto de estudo conhecido como economia política. De fato, todas as esferas da sociedade discutidas aqui estavam entrelaçadas; um dos aspectos distintivos da sociedade ocidental do final do século XIX e do século XX é a separação no espaço público da economia, política, cultura e religião. As ciências sociais separaram a economia política em ciência econômica e ciência política, divisão em muitos aspectos artificial, ao passo que ética e religião foram interpretadas como disciplinas subjetivas, impróprias para julgamento racional. Em virtude disso, muitos aspectos tratados a seguir poderiam ser postos em uma ou outra seção.

\section{Tempo e domínio privado}

As implicações econômicas do tempo geológico são generalizadas e inevitáveis. Uma ampla gama de fatores financeiros pode ser mais bem compreendida por meio da perspectiva de tempo geológico. A sociedade humana depende de muitos materiais naturais que foram formados ao longo do tempo geológico em condições difíceis ou impossíveis de ser reproduzidas. Os recursos vão desde fontes 
de energia (p.ex., petróleo, carvão), a materiais de construção (p.ex., agregados tais como areia e brita), até outras necessidades básicas da vida (p.ex., solos, aquíferos e o próprio ar que respiramos).

Consideremos que alguns centímetros de solo superficial formam-se em períodos de 100 a 10.000 anos, contudo a economia das práticas agrícolas de Iowa ou de qualquer outro lugar externalizam largamente este fato. As taxas de erosão médias são de cinco toneladas por acre ao ano (ou, poucos centímetros a cada 33 anos, a espessura de uma moeda por ano) - mas nada disso acha-se incorporado ao preço do milho. Da mesma forma, cronometrar o tempo de pico do petróleo, identificar mudanças em recursos hídricos limitados (p.ex., o Aquífero Ogallala) e calcular o impacto de eventos climáticos severos, são apenas alguns exemplos nos quais a perspectiva do tempo profundo deveria afetar o ponto de partida (mas que, infelizmente, não afeta).

As implicações econômicas do tempo profundo levantam questões sobre a prática econômica de desconto do futuro. A economia em si sofre de um abreviado horizonte temporal. Conforme expresso nas taxas de juros, cada ano no futuro é descontado em $4 \%, 5 \%$ ou $7 \%$. Uma taxa de juros de $5 \%$ (ou desconto) significa que a cada 14 anos o valor da substância - p.ex., petróleo ou água - é cortado pela metade. A essa taxa, o valor presente de uma substância irá diminuir em 99\% em 100 anos e em 99,999\% em 225 anos - números que se aproximam do âmbito do tempo geológico.

Naturalmente, é improvável que a sociedade queira calcular o custo da erosão dos solos ou a perda de um aquífero nos próximos 100 ou 1.000 anos. Entretanto, isso levanta uma questão importante, salientando a necessidade de se buscar modos de integrar o prazo longo imediato do tempo geológico dentro de nosso planejamento econômico, pelo menos em termos de limites ou regulamentos de nossos hábitos econômicos. Só podemos imaginar a profunda alteração da nossa economia se os economistas forem apresentados ao tempo geológico como algo natural.

\section{Tempo e domínio público}

Chamamos domínio público a relação entre tempo profundo e a tomada de decisões públicas. A fim de serem adequadamente enquadradas, questões como mudança climática, esgotamento de recursos e a perda da biodiversidade exigem as perspectivas de tempo geológico. Além disso, os geocientistas encontram-se hoje presos às mesmas forças que afetam as ciências como um todo: uma crescente ênfase na relevância pública e social da ciência básica.

O crescimento do foco sobre os efeitos sociais da ciência - codificados nos critérios de amplos impactos contidos na revisão por pares exigidos pelo National Science Foundation - ressalta a necessidade de os cientistas pensarem sobre as mais amplas consequências de sua pesquisa. Os cientistas devem fazer conexões explícitas entre as pesquisas que estão realizando e seu uso pela sociedade que as financia.

Isso requer que fomentemos maior consciência entre nossos estudantes sobre as dimensões de políticas públicas vinculadas às Geociências. Consideremos os exemplos relacionados das políticas de energia e de ambiente dos EUA. Cada uma delas, e ambas em conjunto, dependem de nossa capacidade de enquadrar a tomada de decisões em termos do conhecimento e perspectivas descobertas por geocientistas. Uma percepção da ampla extensão de tempo necessária para a criação de combustíveis fósseis é crucial para a formulação de políticas, p.ex., para o estabelecimento de normas de eficiência de combustíveis automotivos. É fato que nos últimos 10.000 anos estamos vivendo um período interglacial de clima relativamente quente que eventualmente está terminando. Portanto, novamente temos um debate sobre o futuro da mudança climática em termos de tempo de resiliência de gases estufa na atmosfera (Archer 2005). Em suma, nossas decisões atuais devem ser postas dentro de estrutura que inclua o passado e o futuro em termos de tempo geológico.

\section{Tempo no domínio cultural}

Assinalamos a importância dos maiores aspectos sociais do tempo geológico em termos econômicos e de decisão política - elementos usualmente inter-relacionados. Entretanto, qualquer relato dos maiores efeitos de se compreender o tempo profundo também deve reconhecer o poder de uma terceira dimensão, o que podemos chamar de dimensões culturais do tempo geológico.

Um dos debates mais antigos dentro da cultura ocidental recai sobre a identificação dos aspectos fundamentais da natureza humana. Desde Adam Smith no século XVIII, a cultura ocidental foi favorecida pela definição de Homo economicus - que assinala nossa natureza fundamental associada à produção e aquisição de bens. Nos séculos XX e agora XXI, isso conduziu à criação da sociedade de consumo de massa, primeiro na Europa e América do Norte e, agora, ao redor do mundo, e um foco irresistível 
em bens materiais. Como economistas e geólogos têm apontado, é improvável a ocorrência de uma sociedade global de consumo - segundo algumas estimativas, isso exigiria recursos naturais de quatro ou cinco Terras somente para suprir a China e a Índia com os mesmos padrões de vida dos EUA.

Isso sugere que o Homo economicus pode estar atingindo seu fim de sua vida útil, causando uma reavaliação de nosso sentido de como devemos ordenar nossas vidas. É bem possível que sejamos forçados a repensar formas mais tradicionais de avaliar o que é uma vida rica e frutífera, como a afirmação de Aristóteles de que a nossa fonte mais básica de prazer é a simples experiência de admirar a natureza das coisas. Dentro de tal visão de mundo, as geociências, e particularmente o tempo geológico, terão muito a oferecer.

Consideremos este pequeno conjunto de maravilhas geológicas: a seca e o posterior reenchimento do Mar Mediterrâneo há 6 milhões de anos (6 Ma) (Hsü 1983); as grandes inundações resultantes da quebra da barragem de gelo do Lago Glacial de Missoula em Montana (http://vulcan.wr.usgs.gov/Glossary/Glaciers/IceSheets/description_lake_missoula. html); o fato de que o local onde hoje está situada Chicago esteve sob milhares de metros de gelo 20.000 anos atrás; ou que o Parque Nacional de Yellowstone é uma caldeira borbulhante que explodiu três vezes nos últimos $2 \mathrm{Ma}$, e está lentamente se enchendo de magma novamente. São todos fatos surpreendentes para ser ponderados, com destaque para os aspectos estéticos dos processos geológicos ao longo do tempo.

Nem todos os exemplos devem estar em lugares distantes: o tempo geológico está sempre bem debaixo de nossos pés. Existem exemplos locais: na área central de Iowa, os estudantes a caminho da escola todo dia caminham sobre restos de oceanos de $300 \mathrm{Ma}$ que oferecem a oportunidade de mudar sua experiência de vida cotidiana. ${ }^{12}$

\section{TRAZENDO O TEMPO PROFUNDO PARA DENTRO DA SALA DE AULA}

Algumas recomendações de como superar os desafios podem ser encontradas na literatura de Educação em Geociências. Usando o tempo como estrutura, podemos unir eventos específicos para criar sequências imaginárias sem recorrer a

12 NR. Estudantes quando andam em Campinas algumas vezes caminham sobre mares, praias que existiram ali perto de $280 \mathrm{Ma}$, quando 0 clima era muito mais frio que 0 atual, quando geleiras avançaram e recuaram deixando seus registros e depósitos que reconhecemos hoje. números, como foi mostrado com sucesso (p.ex., Dodick e Orion 2003a, 2003b, 2006, Dodick 2007). A experiência física de caminhar em um museu de história natural, examinando com atenção fósseis ordenados em sequência de tempo, traduz a experiência de tempo em fenômeno vivo. Os estudantes, dessa forma, podem iniciar com algo concreto antes de anexar seu conhecimento a uma estrutura de apoio fornecida por conjuntos numéricos (p.ex., Dodick 2007). Shea (2001) descreveu uma maneira elegante de apresentar aos estudantes universitários a matemática da datação radiométrica, usando os valores brutos de isótopos pais e filhos, e orientando os alunos passo a passo ao longo de cálculos que conduzem à idade dos espécimes. A abordagem fornece um contexto mais rico para a técnica exposta em livros de texto, nos quais o processo é suavizado por meio de tabelas e torna-se, essencialmente, passivo. (Animações de decaimento radioativo e datação de rochas podem ser encontrados em http://serc.carleton.edu/index. html). Entretanto, pesquisas adicionais poderiam ajudar a demonstrar que as metáforas são bem sucedidas em fornecer aos estudantes um modelo mental de tempo profundo e descobrir se os estudantes então aplicam esse modelo mental quando pensam em questões sociais. ${ }^{13}$

\section{CONCLUSÃO}

Defendemos que é fundamental que todos os estudantes - de Geociências ou não - sejam expos-

13 NR. Se tomamos por referência a História da Ciência, o fazer Geologia mudou a concepção de planeta e de natureza. 0 conhecimento da Terra mudou de caráter, de espaço central de produção de conhecimento (de trabalho em gabinetes e museus com coleções de objetos naturais para atividades de campo) e de suas interconexões com atividades econômicas (se aproximando decisivamente da prospecção mineral e mineração) nas últimas décadas do século XVIII e início do XIX. Evidentemente esse movimento econômico e tecnológico se inter-relacionou a motivações sociais, políticas e culturais mas, simultaneamente, indica pistas que podem ser seguidas pelo ensino de Ciências da Terra.

As transformações das ideias de espaço e tempo foram articuladas ao fato da atividade de campo ter se tornado mais comum. Isso trouxe dinâmicas cognitivas e culturais que adensaram a ideia de tempo da natureza. Em termos conceituais, isso gerou convergência da Geognose e da Mineralogia (com seu sentido e abrangência vigente na segunda metade do século XVIII). Vários autores examinaram essas dimensões históricas e intelectuais (Greene 1982, Rudwick 2005). 0 fazer Geologia pode servir de inspiração para tarefas intelectuais que podem ser propostas a estudantes e dessa forma ajudar a formar certa concepção de natureza e inter-relações sociais que levem em conta o tempo geológico, bem como suas implicações para as dimensões social, política e cultural. Ver: Greene M.T. 1982. Geology in the nineteenth century: changing views of a change world. Ithaaca: Cornell University Press, 324p. Rudwick M.J.S. 2005. Bursting the limits of time: the reconstruction of Geohistory in the Age of Revolution. Chicago: The University of Chicago Press, 708p. 
tos às amplas dimensões econômicas, políticas e culturais de tempo profundo. Delineamos algumas das razões pelas quais os estudantes têm concepções alternativas de tempo e procuramos destacar porque os seres humanos encontram dificuldades para compreender o tempo profundo e a importância de eventos de frequência baixa. Organizamos nosso argumento em torno da importância da motivação, contexto e interesse. Concluímos com dois exemplos finais para mostrar como conduzir esses argumentos em sala de aula.

Consideremos o caso de Nova Orleans e o furacão Katrina. Logo após o furacão, o debate imediato se concentrou em se e como reconstruir a cidade. Porém, a discussão sobrevalorizou questões de custo, possibilidade de adequação dos diques e probabilidade de outro furacão de categoria 3, 4 ou 5 atingir Nova Orleans. Se os debatedores estivessem familiarizados com o tempo geológico e trazido a questão para o processo de tomada de decisão, eles teriam percebido que a probabilidade de outro furacão de categorias 4 e 5 atingir Nova Orleans nas próximas décadas seria de aproximadamente $100 \%$.

Outro fator que permaneceu quase que totalmente ausente da discussão foi a questão da viabilidade a longo prazo de Nova Orleans a partir de outra fonte: o destino do Rio Mississipi. Um mapa do delta do Mississipi mostra como o curso do rio variou centenas de quilômetros ao longo de vários séculos. Além disso, o curso atual do Mississipi é antigo, destinado a mover-se em breve para oeste, através do canal de Atchafalaya. De fato, é somente por causa do enorme esforço do corpo de engenharia do exército dos EUA que o rio mantém seu curso antigo passando por Baton Rouge e Nova Orleans. Sem o contínuo investimento de dinheiro e trabalho (alcançando mais de 35 bilhões de dólares até hoje), o Mississipi teria abandonado as duas cidades durante a década de 1950 (veja Coleman, Roberts e Stone 1998). É uma certeza geológica que ao final o rio fluiria através do Atchafalaya, deixando ambas as cidades como remansos.

Contudo, a perspectiva desses fatos geológicos e hidrológicos pouco ou nada contribuiu para o debate público sobre o futuro de Nova Orleans. Por outro lado, isso não significa sugerir que seria suficiente o conselho da cidade manusear o mapa geológico do delta do Mississipi. Em vez disso, seria muito melhor que estudantes, cidadãos, economistas, políticos pudessem compreender a experiência propiciada pelo tempo geológico passo a passo.
Outro exemplo é propiciado pelo terremoto seguido de tsunami em Sumatra no dia 26 de dezembro de 2004 que causou quase 300.000 mortes. Muitas vidas poderiam ter sido salvas no Oceano Índico se houvesse um sistema de alerta similar ao que existe no Oceano Pacífico. Por outro lado, um estudo detalhado de antigos depósitos deixados por tsunamis nas costas do nordeste de Sumatra sugere que esses eventos ocorrem a cada 600 anos (Monecke et al. 2008). A recorrência pouco frequente pode sugerir que a consciência continuada sobre os perigos do tsunami informada por registros geológicos dos eventos pode ser mais eficaz nesta região do que grandes investimentos em sistemas de alarme de larga escala.

Exemplos tais como Katrina e Nova Orleans destacam o que está em jogo ao enquadrar o tempo geológico dentro do contexto econômico, político e cultural. Naturalmente sempre fazemos alguma coisa sobre isso. Crianças aprendem muito cedo que a idade de uma árvore pode ser encontrada contando os anéis de crescimento em um tronco; nós então podemos transferir esse entendimento para escalas de tempo mais longas, usando as camadas anuais em um núcleo de gelo ou as camadas sazonais em depósitos de varves, mas precisamos dar aos estudantes o que podemos chamar de uma experiência humanista de tempo profundo para ajudá-los a fazer as abstrações de tempo geológico mais reais e mais significativas para suas vidas.

Colocar o tempo profundo em um contexto histórico oferece outros meios para preencher o fosso entre a percepção humana e geológica de tempo. $\mathrm{O}$ uso da história para dar contexto à Educação em Ciências tem se demonstrado bem sucedido em mudar a concepção do aluno sobre a natureza da ciência (p.ex., Matthews 1994, Heilbron 2002). Uma pesquisa em desenvolvimento na Universidade Estadual de Iowa usa a perspectiva histórica para humanizar a ciência do tempo profundo (Cervato et al. 2005). Resultados preliminares indicam que a abordagem é bem sucedida em aumentar o nível de conforto com o tempo geológico em estudantes de áreas não científicas, tecnológicas e de engenharia. Mais ideias e recursos da abordagem podem ser achados em http://serc.carleton.edu/ introgeo/earthhistory/index.html.

Muitos antes de nós (p.ex., McPhee 1981, Gould 1987, ver também Frodeman 1995) argumentaram que a perspectiva temporal da Geologia é crucial para desenvolver modelos para a futura sustentabilidade do planeta. Nossa revisão das 
metodologias em uso para ensinar tempo geológico e a avaliação de técnicas para avaliar o entendimento dos estudantes sobre tempo geológico mostram que poucas alternativas (ou nenhuma delas) são orientadas explicitamente para promover a perspectiva de tempo geológico e aplicá-la aos problemas de sustentabilidade. Tempo profundo traz o registro da frequência, magnitude, recorrência de eventos tais como terremotos, vulcanismo, enchentes e furacões que são elementos necessários para avaliar o risco e inventariar recursos. Entretanto, encontramos muito poucos exemplos nos quais o ensino de Geociências influenciou a economia ou a política, e são necessárias mais pesquisas para testar a efetividade das atuais abordagens de ensino.

Esperamos que este artigo possa inaugurar um programa comum de pesquisa que reúna geocientistas, humanistas, economistas e analistas políticos para usar de modo mais completo o significado do tempo geológico. Devemos gastar menos esforço para ensinar estudantes a pensar sobre o passado e mais esforço para ensinar estudantes a pensar sobre o futuro, usando o tempo geológico passado como guia.

\section{Agradecimentos}

Agradecemos aos membros do Grupo Sinteses (Chuck Goodwin, Lynn Liben, Dave Mogk, Tim Spangler, Neil Stillings, Sarah Titus) e especialmente aos chefes de projeto, Kim Kastens e Cathy Manduca por incentivar, inspirar e encorajar a elaboração deste manuscrito. Reconhecemos, ainda, Rick Duschl, Stephanie Pfirman, Tim Shipley e Mike Taber pelos comentários às primeiras versões do manuscrito. Somos gratos a Jeff Dodick e aos revisores anônimos pelos comentários instigantes durante o processo de publicação. Finalmente, este trabalho teve apoio parcial do National Science Foundation (DRL-0722268 e DRL-072238).

\section{Referências}

Archer D. 2005. The fate of fossil fuel CO2 in geologic time. Journal of Geophysical Research, 110.

Ault C.R., Jr. 1982. Time in geological explanations as perceived by elementary-school students. Journal of Geological Education, 30:304-309.

Boroditsky L. 2000. Metaphoric structuring: Understanding time through spatial metaphors. Cognition, 75:1-28.

Carlyle T. 1832. Fraser's Magazine. May 406/1, in Oxford English Dictionary: http:/dictionary.oed.com/ cgi/entry/20002670? single $=1 \&$ query_type $=$ wor $\mathrm{d} \&$ queryword $=$ deep + time\&fi $\mathrm{rst}=1 \& \max$ to show $=10$. Accesso em 29.05.2009.

Cervato C. et al. 2005. Humanizing science to improve undergraduate education: Short stories on geologic time. Geological Society of America Abstracts with Programs, 37(7):153.

Coleman J.M., Roberts H.H., and Stone G.W. 1998. Mississippi River Delta; an overview. Journal of Coastal Research, 14:698-716.

Day J.W. et al. 2007. Restoration of the Mississippi Delta: Lessons from Hurricanes Katrina and Rita. Science, 315:1679-1684.

Dodick J. 2007. Understanding evolutionary change within the framework of geologic time. McGill Journal of Education, 42:245-264. Downloaded from specialpapers.gsapubs.org 06.06.2012.

Dodick J., Orion N. 2003a. Cognitive factors affecting students' understanding of geological time. Journal of Research in Science Teaching, 40:415-442.

Dodick J., Orion N. 2003b. Measuring student understanding of geological time. Science Education, 87:708-731.

Dodick J., Orion N. 2006. Building an understanding of geological time: A cognitive synthesis of the macro and micro scales of time. In: Manduca C.A., Mogk D.W. Ed. Earth and Mind: How Geologists Think and Learn about the Earth. Geological Society of America, Special Paper 413, p.77-94.

Foltz B.V. 2000. Inhabitation and orientation: Science beyond disenchantment. In: Frodeman R. Ed. Earth Matters. New Jersey: Upper Saddle River, p.25-34. (The Earth Sciences, Philosophy, and the Claims of Community).

Friedman W.J. 2005. Developmental and cognitive perspective on humans' sense of times of past and future events. Learning and Motivation, 36:145-158.

Frodeman R. 1995. Geological reasoning: Geology as an interpretive and historical science. Geological Society of America Bulletin, 107:960-968.

Frodeman R. 2003. Geo-Logic: Breaking Ground between Philosophy and the Earth Sciences. Albany: State University of New York Press, 192p.

Gallup. 2004. Third of Americans say evidence has supported Darwin's evolution theory. http://www. gallup.com/poll/14107/Third-Americans-Say-Evidence-Has-Supported-Darwins-Evolution-Theory.aspx Accesso 25.06.2008.

Gould S.J. 1987. Time's Arrow, Time's Cycle: Myth and Metaphor in the Discovery of Geological Time. Cambridge, MA: Harvard University Press, 240p.

Hegel G.F.W. 1977. The Phenomenology of Spirit. Oxford, UK: Oxford University Press, 632p. (Tradução por A.V. Miller).

Heidegger M. 1962. Being and Time. London: SCM Press, 589p. (Tradução por J. Macquarrie, E. Robinson).

Heilbron J.L. 2002. History in science education, 
with cautionary tales about the agreement of measurement and theory. Science and Education, 11:321-331.

Hsü K.J. 1983. The Mediterranean was a Desert. Princeton, NJ: Princeton University Press, 216p.

Kant I. 1881. Critique of Pure Reason. London: Macmillan, 785p. (Tradução por F.M. Müller).

Kermode F. 1967. The Sense of an Ending: Studies in the Theory of Fiction. Oxford, UK: Oxford University Press, 200p.

Kolb C.R., Van Lopik R. 1996. Depositional environments of the Mississippi River deltaic plain, southeastern Louisiana. In: Shirley M.L. Ed. Deltas in their geological framework. Houston, TX: Houston Geological Society, p.16-61.

Levstik L.S., Barton K.C. 2005. Doing History: Investigating with Children in Elementary and Middle Schools. $3^{\mathrm{a}}$ ed. Mahwah, NJ: Lawrence Erlbaum Associates, 256p.

Libarkin J. et al. 2005. Qualitative analysis of college students' ideas about the Earth: interviews and open-ended questionnaires. J. Geosc.. Educ., 53:17-26.

Libarkin J., Kurdziel J.P., Anderson S.W. 2007. College student conceptions of geological time and the disconnect between ordering and scale. J. Geosc. Educ., 55:413-422.

Matthews M.R. 1994. Science Teaching: The Role of History and Philosophy of Science. New York: Routledge, 287p.

McClure S. et al. 2004. Separate neural systems value immediate and delayed monetary rewards. Science, 306:503-507.

McIntyre A. 1981. After Virtue: A Study in Moral Theo$r y$. Notre Dame, IN: University of Notre Dame Press, 252p.

McPhee, J. 1981. Basin and Range. New York: Farrar, Straus and Giroux, 224p.

Monecke K. et al. 2008. A 1,000-year sediment record of tsunami recurrence in northern Sumatra. $\mathrm{Na}$ ture, 455:1232-123.
Penn D. 2003. The evolutionary roots of our environmental problems: Towards a Darwinian ecology. The Quarterly Review of Biology, 78:275-301.

Sadler P., Cervato C. 2011. Data and tools for geologic timelines and time scales. In: Keller G.R., Baru C. Ed. Geoinformatics. Cambridge, UK: Cambridge University Press, p.145-165.

Schoon K.J. 1992. Students' alternative conceptions of Earth and space. J. Geosc. Educ., 40:209-214.

Shea J. 2001. Teaching the mathematics of radiometric dating. J. Geosc. Educ., 49:22-24.

Steno N. 1669. De Solido intra Solidum Naturaliter contento Dissertationis Prodromus (Introduction to a Dissertation on Solids Naturally Contained within Solids). Florence: Stellae, 78p.

Tooby J., Cosmides L. 1995. The psychological foundations of culture. In: Barlow J., Cosmides L., Tooby J. Ed. The Adapted Mind: Evolutionary Psychology and the Generation of Culture. New York: Oxford University Press, p.19-136.

Trend R.D. 2001. Deep time frameworks: A preliminary study of U.K. primary teachers' conceptions of geological time and perceptions of Geosc. Journal of Research in Science Teaching, 38:191221.

Tversky A., Kahneman D. 1974. Judgment and uncertainty: Heuristics and biases. Science, 185:11241131.

United States of America. National Research Council. 1996. National Science Education Standards. Washington, D.C.: National Academy Press, 262p.

Ussher J. 1650. Annales veteris testamenti, a prima mundi origine deduction. (Edição moderna em ingles: Annals of the Old Testament, Deduced from the First Origins of the World, editado por L. Pierce and M. Pierce. Green Forest, AK: Master Books, 2003, 960p.).

Zen E. 2001. What is deep time and why should anyone care? J. Geosc. Educ., 49:5-9. 